\title{
Analysis of Methods for Ellipsoidal Height Estimation - The Case of a Local Geodetic Reference Network*
}

\author{
${ }^{1}$ Y.Y. Ziggah, ${ }^{1}$ I. Yakubu and ${ }^{1}$ B. Kumi-Boateng \\ ${ }^{1}$ University of Mines and Technology, P.O. Box 237, Tarkwa, Ghana
}

Ziggah, Y.Y., Yakubu, I. and Kumi-Boateng, B. (2016) "Analysis of Methods for Ellipsoidal Height Estimation - The Case of a Local Geodetic Reference Network”, Ghana Mining Journal, Vol. 16, No. 2, pp. 1 - 9.

\begin{abstract}
Ghana's local geodetic reference network is based on the War Office 1926 ellipsoid with data in latitude, longitude and orthometric height $(\phi, \lambda, H)$ without the existence of ellipsoidal height. This situation makes it difficult to apply the standard forward transformation equation for direct conversion of curvilinear geodetic coordinates $(\phi, \lambda, h)$ to its associated cartesian coordinates $(\mathrm{X}, \mathrm{Y}, \mathrm{Z})$ in the Ghana local geodetic reference network. In order to overcome such a challenge, researchers resort to various techniques to obtain the ellipsoidal height for a local geodetic network. Therefore, this paper evaluates, compares, and discusses different methods for estimating ellipsoidal height for a local geodetic network. The investigated methods are the Abridged Molodensky transformation model, Earth Gravitational Model, and the Orthometric Height approach. To evaluate these methods, their estimated local ellipsoidal height values were implemented in the sevenparameter similarity transformation model of Bursa-Wolf. The performance of each of the methods was assessed based on statistical indicators of Mean Square Error (MSE), Mean Absolute Error (MAE), Horizontal Position Error (HE) and Standard Deviation (SD). The statistical findings revealed that, the Abridged Molodensky model produced more reliable transformation results compared with the other methods. It can be concluded that for Ghana's local geodetic network, the most practicable method for estimating ellipsoidal height is the Abridged Molodensky transformation model.
\end{abstract}

Keywords: Abridged Molodensky Model, Earth Gravitational Model, Orthometric Height, Geodetic Network

\section{Introduction}

Over the years, accurate estimation of ellipsoidal height for a local geodetic network in order to carry out three-dimensional (3D) coordinate transformation has been problematic and has drawn the attention of many researchers. This is because most local geodetic networks were established at a time where satellite positioning techniques have not reached the advanced stage. Hence, measured distances, angles and local datum points were fixed on the basis of astronomical observations, traversing, terrestrial triangulation (ConstatinOctavian, 2006) which is the case in many countries. An example is the case of Ghana during the establishment of its geodetic framework in the first half of the twentieth century. In view of the methods applied, only horizontal positions were estimated and orthometric height determined through levelling for the geodetic network.

Ghana Geodetic Reference Network (GGRN) established through classical methods of surveying is referenced on the War Office ellipsoid with data in latitude, longitude and orthometric height $(\varphi, \lambda, H)$ without the existence of ellipsoidal height. This poses a challenge to apply directly the standard forward transformation equation for direct conversion of geodetic coordinates $(\varphi, \lambda, h)$ to its associated cartesian coordinates $(\mathrm{X}, \mathrm{Y}, \mathrm{Z})$. This forward conversion is necessary since it serves as the intermediate step in transforming Global Navigation Satellite System (GNSS) measurements to a local coordinate system (Vanicek and Steeves 1996; Cai et al., 2011).

Moreover, in determining transformation parameters between global and local datum there is the need to transform geodetic coordinates to cartesian coordinates system before implementing the transformation model. These prompted a variety of approaches to help accurately determine the ellipsoidal height for a local geodetic network.

Generally, the methods mostly applied for estimating the ellipsoidal height for the local geodetic network of countries include; the use of orthometric height, the Abridged Molodensky transformation model and the Earth Gravitational Model (EGM). These techniques have been applied and tested by researchers in some part of the world to determine the local ellipsoidal height in their respective local geodetic datums (Karunaratne, 2007; Al-Ghamdi and Dawod, 2013; Al-Krargy et al., 2014). However, in Ghana, most researchers, (Ayer, 2008; Ayer and Fosu, 2008; Ayer and Tiennah, 2008; Dzidefo, 2011; Ziggah et al., 2013a; 2013b; Kumi-Boateng and Ziggah, 2016) have applied only the Abridged Molodensky method to facilitate in estimating the local geodetic height. 
In view of the above, it can fairly be concluded that orthometric height and EGM approach have not been applied and tested within the Ghana local geodetic datum for estimating ellipsoidal height. In addition, it is well known that the accuracy of the determined local ellipsoidal height have an influence on the final transformed coordinates from the various transformation models utilized. Hence, there is the need to investigate the efficiency of the proposed methods in estimating local ellipsoidal height within Ghana's local geodetic network.

In this context, this paper evaluates, compares, and discusses the different methods of estimating the local ellipsoidal height for a local geodetic network. In order to ascertain the efficiency of the methods, the longitude, latitude and estimated ellipsoidal heights were applied in the Bursa-Wolf transformation model to transform data from World Geodetic System 1984 (WGS84) to War Office 1926 ellipsoid. This study will therefore create the opportunity for geospatial practitioners in Ghana to arrive at a consensus on the most appropriate technique applicable within the local geodetic datum.

\section{Resources and Methods Used}

\subsection{Resources}

The geodetic datum used for surveying and mapping purposes in Ghana is based on the War Office 1926 ellipsoid suggested by the British War Office. The parameters that define the War Office 1926 ellipsoid are: semi-major axis a = $6378299.99899 \mathrm{~m}$, semi-minor axis $\mathrm{b}=$ $6356751.68824 \mathrm{~m}$, flattening $\mathrm{f}=1 / 296$, and feet to meter conversion factor of 0.304799706846 (Ayer, 2008; Ayer and Fosu, 2008). The geodetic datum has data in latitude, longitude and orthometric height $(\varphi, \lambda, H)$. This lack of local ellipsoidal height in local geodetic networks makes it a challenge in utilizing Global Positioning System (GPS) measurements locally. In view of this, PokuGyamfi and Schueler, (2008) proposed the renewal of the old Ghana geodetic reference network. Moreover, such renewal will enable the use of modern and cost effective survey techniques and instrument to meet the growing demand of geodetic surveying in the country (Poku-Gyamfi and Schueler, 2008).
In the light of these developments and other factors, the then Survey Department now Survey and Mapping Division of Lands Commission, Ghana through the Land Administration Project (LAP) embarked on the establishment of the new geodetic reference network (Poku-Gyamfi and Schueler, 2008). In the newly established network (Fig. 1), GPS was used to obtain satellite coordinates defined in the International Terrestrial Reference Frame 2005 (ITRF2005) specified at epoch 2007.39 (Kotzev 2013). This demand-led project has been divided into phases, with the first phase covering five out of the ten regions in Ghana namely; Ashanti, Greater Accra, Western, Central and Eastern. These regions form the completed first phase of the new geodetic reference network (Golden Triangle) as shown in Fig. 1. It is important to note that this present study is been carried out in the Golden Triangle.

In this study, secondary data (Table 1) of geodetic coordinates and orthometric heights acquired from the Ghana Survey and Mapping Division of Lands Commission was used. Two sets of 19 common points which form the new geodetic reference network was provided for both the local War Office $(\phi, \lambda, H)_{W A R}$ and global WGS84 $(\phi, \lambda, h)_{W G S 84}$ system. Where $\phi$ is the latitude, $\lambda$ is the longitude, $h$ is the ellipsoidal height and $\mathrm{H}$ is the orthometric height respectively. It is worth stating that the common point's coordinates on the WGS 84 ellipsoid resulted from latitude, longitude and ellipsoidal height provided by the GPS receiver and differential processing with the International GNSS Service (IGS) data. These data sets were collected during the first Land Administration Project (LAP-1) in 2008 (Dzidefo, 2011; Kotzev, 2013).

The following sections describe the sample collection procedure and the laboratory analysis conducted. 


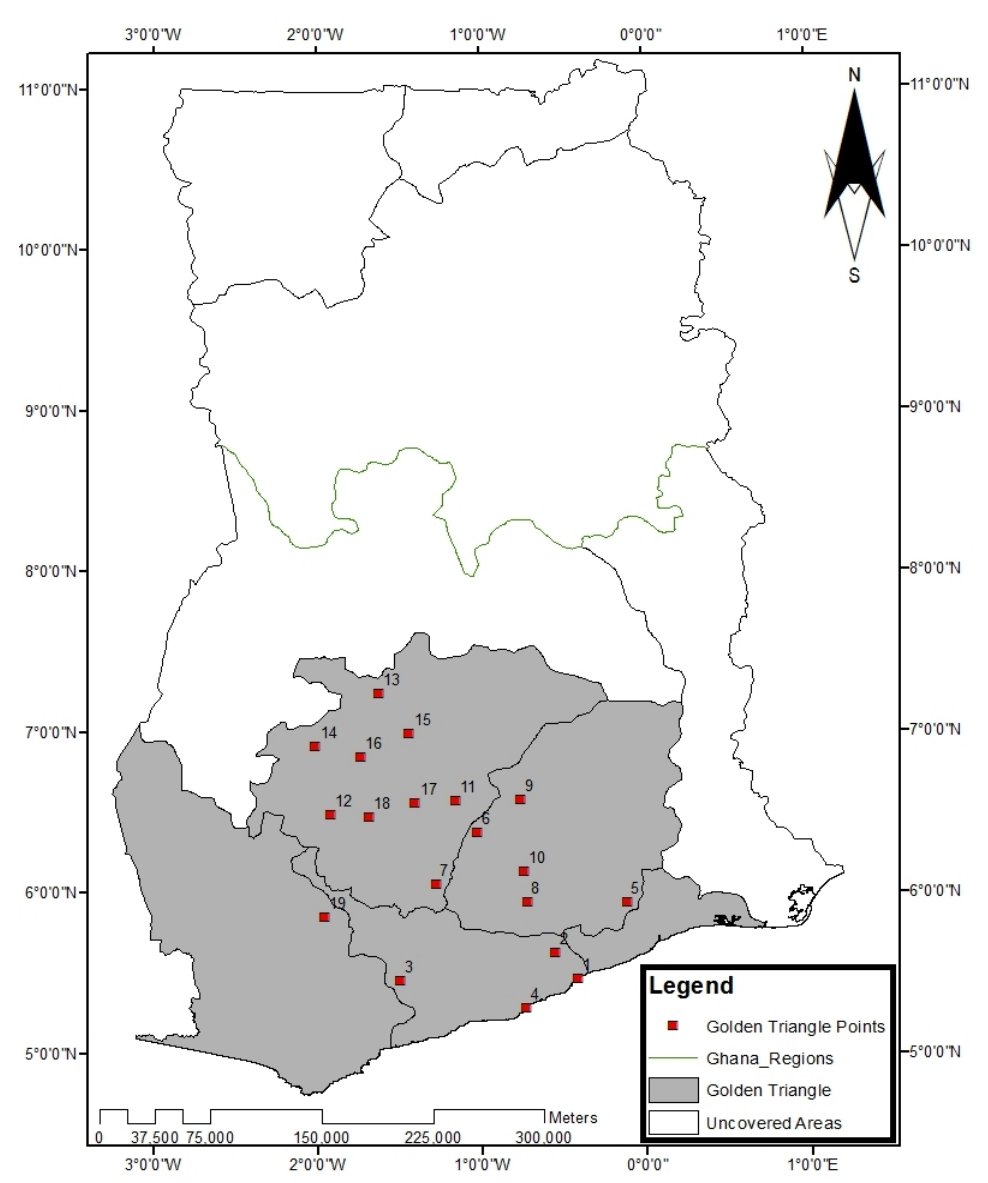

Fig. 1 Study Area: Regions covered by the New Geodetic Reference Network and Coordinates Distribution

Table 1 Golden Triangle Common Point Coordinates

\begin{tabular}{|c|c|c|c|c|c|c|}
\hline PT ID & WAR_LONG & WAR_LAT & WAR_HEIGHT & WGS_LONG & WGS_LAT & WGS_HEIGHT \\
\hline $\mathrm{P} 1$ & -0.423846053 & 5.457304069 & 82.06617254 & -0.423560461 & 5.460090469 & 78.2744 \\
\hline $\mathrm{P} 2$ & -0.559597439 & 5.623015028 & 307.9118986 & -0.559316989 & 5.625798375 & 304.9379 \\
\hline P3 & -1.501354089 & 5.452274171 & 279.5251808 & -1.501101706 & 5.455086786 & 275.1437 \\
\hline P4 & -0.122290556 & 5.936246667 & 525.5954331 & -0.121995097 & 5.939034008 & 524.5492 \\
\hline P5 & -1.033574469 & 6.369342009 & 491.7308587 & -1.033307164 & 6.372117933 & 492.5083 \\
\hline P6 & -0.729977811 & 5.940330581 & 312.4534035 & -0.729704947 & 5.943106975 & 311.0926 \\
\hline P7 & -0.765843033 & 6.573034939 & 780.2024389 & -0.765572008 & 6.575796806 & 782.2084 \\
\hline P8 & -0.749175303 & 6.125418053 & 327.4003755 & -0.748904353 & 6.12819705 & 327.0218 \\
\hline P9 & -1.164931611 & 6.568591978 & 613.9824331 & -1.164662747 & 6.571357297 & 615.7568 \\
\hline P10 & -1.630716606 & 7.233128636 & 530.9263781 & -1.630465086 & 7.235861019 & 536.0062 \\
\hline P11 & -2.017006497 & 6.909735047 & 557.6480689 & -2.016757894 & 6.912480178 & 560.8285 \\
\hline P12 & -1.445590708 & 6.989461464 & 617.0558219 & -1.445337764 & 6.992208703 & 620.9316 \\
\hline P13 & -1.743673061 & 6.843594833 & 414.0673431 & -1.743417842 & 6.846343694 & 417.0231 \\
\hline P14 & -1.695085044 & 6.468790536 & 471.1630008 & -1.69483105 & 6.471557664 & 472.143 \\
\hline $\mathrm{P} 15$ & 0.734677778 & 5.27995835 & 88.36929587 & 0.734406006 & 5.282744181 & 83.4515 \\
\hline $\mathrm{P} 16$ & 1.286464464 & 6.051006676 & 438.7548656 & 1.286211228 & 6.053791594 & 437.699 \\
\hline P17 & 1.925406333 & 6.482004197 & 642.6333852 & 1.925156364 & 6.484775481 & 643.5756 \\
\hline P18 & 1.412160561 & 6.554147306 & 502.1391431 & 1.411897078 & 6.556916419 & 503.7124 \\
\hline P19 & 1.966403494 & 5.846824211 & 401.8271718 & 1.966153267 & 5.849618067 & 399.3477 \\
\hline
\end{tabular}




\subsection{Methods}

\subsubsection{Abridged Molodensky Model}

The Abridged Molodensky is a standard model of coordinate transformation. It enables latitudes, longitudes and heights related to one ellipsoid to be transformed to latitudes, longitudes and heights related to another ellipsoid on the implicit assumptions that (Deakin, 2004):

(i) the $\mathrm{X}, \mathrm{Y}, \mathrm{Z}$ cartesian axes of both systems are parallel;

(ii) the coordinate differences $\Delta \mathrm{X}, \Delta \mathrm{Y}, \Delta \mathrm{Z}$ between the origins of the reference ellipsoids are known; and

(iii) the defining geometric parameters of both reference ellipsoids are known.

The Abridged Molodensky uses the relative location of the geometry centres of the source and target ellipsoids (Molnár and Tilmár, 2005).

The formulae for the Abridged Molodensky is given by Equations 1 to 3 as

$$
\begin{aligned}
& \Delta \varphi=\frac{1}{\rho}\left(\begin{array}{l}
-\Delta X \sin \varphi \cos \lambda-\Delta Y \sin \varphi \sin \lambda \\
+\Delta Z \cos \varphi+(f \Delta a+a \Delta f) \sin 2 \varphi
\end{array}\right) \\
& \Delta \lambda=\frac{1}{N \cos \varphi}(-\Delta X \sin \lambda+\Delta Y \cos \lambda) \\
& \Delta h=\Delta X \cos \varphi \cos \lambda+\Delta Y \cos \varphi \sin \lambda \\
& +\Delta Z \sin \varphi-a+(f \Delta a+a \Delta f) \sin ^{2} \varphi
\end{aligned}
$$

with

$$
\begin{gathered}
\rho=\frac{a\left(1-e^{2}\right)}{\left(1-e^{2} \sin ^{2} \varphi\right)^{\frac{3}{2}}}, N=\frac{a}{\left(1-e^{2} \sin ^{2} \varphi\right)^{\frac{1}{2}}}, \text { and } \\
e^{2}=2 f-f^{2} .
\end{gathered}
$$

where:

$a=$ semi-major axis of the War Office 1926 ellipsoid.

$f=$ flattening of the War Office 1926 ellipsoid.

$\rho=$ radius of curvature in the meridian.

$N=$ radius of curvature in the prime vertical plane.

$e=$ first eccentricity of the reference ellipsoid.

$(\varphi, \lambda, h)=$ geodetic coordinates with respect to the War Office 1926 ellipsoid.

$(\Delta \varphi, \Delta \lambda, \Delta h)=$ corrections to transform global geodetic coordinates based on WGS84 to $(\varphi, \lambda, h)$
$(\Delta X, \Delta Y, \Delta)=$ corrections to transform global rectangular coordinates based on WGS84 to War Office 1926 system.

$\Delta a, \Delta f=$ differences between the semi-major axis and flattening of WGS84 ellipsoid and War Office 1926 ellipsoid respectively.

After executing Equations 1 to 3, the War Office 1926 ellipsoidal height was calculated using the relation (Equation 4)

$$
h_{W a r}=h_{W G S 84}-\Delta h
$$

where $h_{W G S 84}$ is the GPS ellipsoidal height based on WGS84, $\Delta h$ is the ellipsoidal height correction factor to transform $h_{W G S 84}$ to $h_{W a r}$. Here, $h_{W a r}$ is the ellipsoidal height to be determined for the War Office 1926 ellipsoid.

\subsubsection{Earth Gravitational Model (2008)}

The Earth Gravitational Model 2008 (EGM2008) is the latest effort by NGA (National Geospatial Intelligence Agency, USA) at generating an accurate global geoid height model for converting geocentric ellipsoidal heights to its corresponding orthometric height (Uzodinma et al., 2014). It is complete to spherical harmonic degree and order 2159, and contains additional coefficients extending to degree 2190 and order 2159. It represents the highest resolution to date of $5^{\prime} \times 5^{\prime}$ of arc (approximately $9 \mathrm{~km} \times 9 \mathrm{~km}$ ) (Pavlis et al., 2008; Pavlis et al., 2012; Odera, 2016). In addition, it is supplied with a conversion model complete to degree and order 2160 for converting height anomalies to geoid undulations (Pavlis et al., 2012).

This study applied the EGM2008 to calculate the geoidal undulation of the control points. The geometric relation between the geoid, ellipsoid and the topography was then applied to estimate the ellipsoidal height for the Ghana local geodetic network. Thus; $h=H+N$ where $h$ is the ellipsoidal height to be estimated; $H$ is the orthometric height within the local geodetic network and $N$ is the geoidal undulation value determined based on the EGM 2008

The latitudes $\phi$, longitudes $\lambda$ and the ellipsoidal heights $h$ were then converted to its associated cartesian coordinates (X, Y, Z) using standard forward transformation equation (Jekeli, 2012) represented in Equation 5 as:

$$
\begin{aligned}
& X=(N+h) \cos \varphi \cos \lambda \\
& Y=(N+h) \cos \varphi \sin \lambda \\
& Z=\left[N\left(1-e^{2}\right)+h\right] \sin \varphi
\end{aligned} .
$$




\subsubsection{Orthometric Height Method}

The Orthometric Height Method (OHM) employs a direct conversion of latitudes $\phi$, longitudes $\lambda$ and Orthometric Height $(H)$ in the local geodetic network to its associated cartesian coordinates using the standard forward equation. It is mathematically given by Eqn. (6) as:

$$
\begin{aligned}
& X=(N+H) \cos \varphi \cos \lambda \\
& Y=(N+H) \cos \varphi \cos \lambda \\
& Z=\left[N\left(1-e^{2}\right)+H\right] \sin \varphi
\end{aligned}
$$

It should be noted that although Equations 5 and 6 are mathematically equivalent, both equations apply different height input parameters. That is, in Equation 6 ellipsoidal height was replaced with orthometric height $(\mathrm{H})$ values.

\subsubsection{Bursa-Wolf Transformation Model}

The Bursa-Wolf model is a three-dimensional (3D) conformal coordinate transformation generally used by geodetic practitioners to relate two different 3D geodetic systems. One of the characteristic feature of conformal transformation models is that true shape is retained after transformation (Ghilani and Wolf, 2006) hence angles are not changed, but the lengths of lines and position of points may be changed (ConstantinOctavian, 2006). The Bursa-Wolf model also known as the seven-parameter model combine a scale change, three axes rotations and three originshifts to relates points in two different 3D coordinate systems. The Bursa-Wolf transformation model (Deakin, 2006) may be written as (Eqn. 7)

$$
\left[\begin{array}{c}
X \\
Y \\
Z
\end{array}\right]_{2}=(1+\Delta s)\left[\begin{array}{ccc}
1 & \varepsilon_{Z} & -\varepsilon_{Y} \\
-\varepsilon_{Z} & 1 & \varepsilon_{X} \\
\varepsilon_{Y} & -\varepsilon_{X} & 1
\end{array}\right]\left[\begin{array}{c}
X \\
Y \\
Z
\end{array}\right]_{1}+\left[\begin{array}{c}
t_{X} \\
t_{Y} \\
t_{Z}
\end{array}\right]
$$

where $[X, Y, Z]_{2}^{T}$ is the coordinate in the War Office system and $[X, Y, Z]_{1}^{T}$ is the coordinate in the WGS84 system. $\varepsilon_{X}, \varepsilon_{Y}, \varepsilon_{Z}$ are the rotation parameters, $\left[t_{X}, t_{Y}, t_{Z}\right]^{T}$ are the translation parameters and $\Delta s$ is the scale factor.

In this study, the least squares adjustment technique was used to determine the seven transformation parameters (scale, rotations and translations) in the Bursa-Wolf model. The determined parameters were then used to transform WGS84 data into Ghana geodetic datum (War Office).

\subsection{Model Performance Assessment}

In order to compare the results obtained from the EGM, OHM and Abridged Molodensky model, the residuals computed between the measured projected grid coordinates and the transformed grid coordinates were used. The statistic indicators used include the Mean Squared Error (MSE), Mean Absolute Error (MAE), Horizontal Position Error (HE), Mean Horizontal Position Error (MHE) and Standard Deviation (SD). The mathematical expression for the various performance indices are given by Equations 8 to 12 respectively.

$$
\begin{aligned}
& M S E=\frac{1}{n} \sum_{i=1}^{n}\left(O_{i}-P_{i}\right)^{2} \\
& M A E=\frac{1}{N} \sum_{i=1}^{N}\left|O_{i}-P_{i}\right| \\
& H E=\sqrt{\left(E_{2}-E_{1}\right)^{2}+\left(N_{2}-N_{1}\right)^{2}} \\
& M H E=\frac{1}{n} \sum_{i=1}^{n} H E_{i} \\
& S D=\sqrt{\frac{1}{n-1} \sum_{i=1}^{n}(e-\bar{e})^{2}}
\end{aligned}
$$

With reference to Equations (8) to $12, n$ is the total number of points, $O$ and $P$ are the existing projected grid coordinates and transformed projected grid coordinates produced by the various methods applied. $e$ represent the residuals between the existing and transformed projected grid coordinates and $\bar{e}$ is the mean value of the residuals. || in Equation 9 represents the absolute value of the residuals estimated between $O$ and $P$.

\section{Results and Discussion}

In order to check the efficiency of EGM, OHM and Abridged Molodensky, residuals between the measured projected grid coordinates and the new projected grid coordinates produced by the three methods were estimated. The authors deem it appropriate to use the planar coordinate's values in the analysis because Ghana uses a horizontal geodetic datum for its geospatial activities. Hence, the objective here is to ascertain the extent of accuracy achievable for a particular ellipsoidal height estimation method (EGM, OHM and Abridged Molodensky) in the final transformed planar coordinates within Ghana's geodetic reference network. Statistical indicators presented in Section 2.2.5 were then used to quantify these residuals generated for results interpretation. Table 2 presents the statistical results for the three methods. 
Table 2 Performance Analysis of the three Methods

\begin{tabular}{|c|c|c|c|c|}
\hline \multirow{2}{*}{ Method } & \multicolumn{2}{|c|}{ MSE } & \multicolumn{2}{c|}{ MAE } \\
\cline { 2 - 5 } & $\Delta \mathbf{E}$ & $\Delta \mathbf{N}$ & $\Delta \mathbf{E}$ & $\Delta \mathbf{N}$ \\
\hline EGM & 11.696 & 5.754 & 2.750 & 1.936 \\
\hline OHM & 11.645 & 5.733 & 2.745 & 1.933 \\
\hline $\begin{array}{c}\text { Abridged } \\
\text { Molodensky }\end{array}$ & 0.219 & 0.704 & 0.408 & 0.722 \\
\hline
\end{tabular}

In this study, the MSE and MAE were used as an optimality criterion to aid in selecting the ellipsoidal height method that is most suitable to be used in the transformation between global datum and Ghana local geodetic datum. These statistical indices are capable of quantifying the size of the error produced by the ellipsoidal height estimation methods outputs from the measured data. Hence, the closer these statistical indices are to zero the better the prediction capabilities of the method.

Taking into account the MSE and MAE results (Table 2), it was uncovered that, the Abridged Molodensky outperformed the OHM and EGM since Abridged Molodensky produced the lowest MSE and MAE values, while OHM and EGM suffered from higher values. By virtue of the results (Table 2), it can obviously be concluded that the predicted outputs rendered by the Abridged Molodensky are significantly close to the measured data. A summary of the total horizontal error obtained using EGM, OHM and Abridged Molodensky is presented in Table 3.

Table 3 Total Horizontal Residuals of the Coordinate Differences using the Three Methods

\begin{tabular}{|c|c|c|c|}
\hline EPI & EGM & OHM & $\begin{array}{c}\text { Abridged } \\
\text { Molodensky }\end{array}$ \\
\hline MHPE & 3.694 & 3.687 & 0.882 \\
\hline Max & 7.802 & 7.779 & 1.807 \\
\hline Min & 0.817 & 0.815 & 0.151 \\
\hline SD & 2.004 & 1.999 & 0.393 \\
\hline
\end{tabular}

Table 3 shows that in the case of estimating the local ellipsoidal heights, the Abridged Molodensky approach is dominant over the OHM and EGM. This is in line with the Abridged Molodensky attaining the least MHPE (Table 2). Hence, indicating a substantial improvement in horizontal positional accuracy of the transformed projected grid coordinates given by the Abridged Molodensky model compared to the OHM and EGM. This assertion conforms to Fig. 2 where the HEs are displayed.

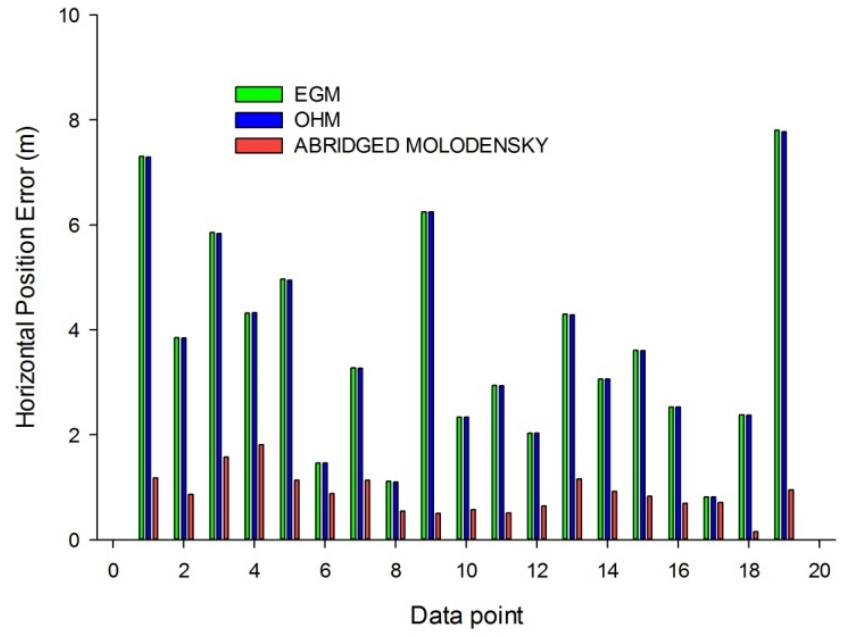

Fig. 2 Two-dimensional horizontal position error

The estimated SD values (Table 3) show a practical expression for the precision of the outputs from the EGM, OHM and Abridged Molodensky methods. In Table 3, it was known that the Abridged Molodensky was again superior to the EGM and OHM because, Abridged Molodensky had the least $\mathrm{SD}$ values. These SD values further indicate that in the case of the Abridged Molodensky approach, the limit of the error bound by which every value within the predicted projected grid coordinates varies from its most probable value is $0.393 \mathrm{~m}$. The EGM and OHM showed a variation of $2.004 \mathrm{~m}$ and $1.999 \mathrm{~m}$ from the most probable value. Therefore, on the strength of the SD values obtained by the Abridged Molodensky, it can be indicated that its predicted outcomes are more precise and accurate than the other methods.

The interpretation made in line with the maximum and minimum values (Table 3 ) is that, the Abridged Molodensky transformed coordinates differed by not more than approximately $1.81 \mathrm{~m}$ whereas $7.8 \mathrm{~m}$ and $7.78 \mathrm{~m}$ was realized by the EGM and OHM respectively. A minimum value of approximately $0.15 \mathrm{~m}$ was obtained by the Abridged Molodensky and $0.82 \mathrm{~m}$ attained by both the EGM and OHM respectively. This furthermore gives an indication about the accuracy range of the three methods.

It is noteworthy that the errors generated by the application of the EGM, OHM and Abridged Molodensky may be attributed to some key factors. The first is subject to the issue that the three methods implemented are approximate functions. Hence, from a mathematical point of view, the ideal zero error could not be achieved. Secondly, random errors of the measured data applied for the model formulations have an influence on the outcome of the estimated projected grid coordinates. In addition, the orthometric height is referenced to a physical surface while ellipsoidal 
height is a purely geometric entity. Hence, applying the orthometric height directly as an ellipsoidal height in the standard forward transformation equation for coordinate transformation between global and local datums could lead to higher errors as was observed in this present study. Furthermore, the EGM results obtained have shown that within the study area in Ghana, the efficiency of EGM is just comparable to the OHM. This could be attributed to the influence of the orthometric height in the geometric estimation of the ellipsoidal height from the geoidal undulations given by the EGM.

Conversely, the global goal of centimetre accuracy for the EGM2008 could not be achieved in this study. The present authors are of the view that Ghana's contribution in the form of gravity data to the National Geospatial Agency (NGA) for determining the EGM2008 is at a minimum. Readers can refer to Ziwu (2011). Hence, the EGM results attained within the Ghana geodetic network are not comparable to the results presented by (AlGhamdi, 2013; Al-Krargy, 2014; Uzodinma, 2014; Odera, 2016) in different countries.

\section{Conclusions and Recommendation}

Unification of different geodetic networks onto a common datum is very essential especially in developing countries like Ghana where the geocentric datum is yet to be established and adopted for its surveying and mapping purposes. Ghana is still utilizing the non-geocentric datum which involves data in only latitude and longitude. It is well known that in order to implement GNSS positional measurements locally, the first step in a coordinate transformation procedure is to convert geodetic coordinates into cartesian coordinates. This forward conversion could not be done straightforwardly in a local geodetic network due to lack of ellipsoidal height. The objective of this study is to compare the various methods for estimating ellipsoidal height for a local geodetic network.

To this end, Earth Gravitational Model, Orthometric Height Method and Abridged Molodensky have been presented. The findings revealed that, the Abridged Molodensky model offered more satisfactory transformed coordinate values than the other two methods. It can therefore be proposed that, the Abridged Molodensky model should be used instead of the Orthometric Height Method and Earth Gravitational model in the Ghana's local geodetic network when estimating local ellipsoidal height.

Furthermore, the authors are recommending that the Geological Survey Department should expand the terrestrial gravity data collection to cover the whole of Ghana. This will help determine a precise gravimetric geoid model for Ghana. In effect, accurate and precise height could be estimated rather than using the generalised global EGM2008.

\section{Acknowledgement}

The authors would like to thank the Ghana Survey and Mapping Division of Lands Commission for providing us data to carry out this research work.

\section{References}

Al-Ghamdi, K. A. and Dawod, G. M. (2013), "Accuracy Assessment of Global Geopotential Models for GIS and Geomatics Applications in Makkah Metropolitan Area", Eigth National GIS Symposium in Saudi Arabia, Jumada, KACST Technology Innovation Centre (TIC) of Geographic Information Systems, Umm AlQura University, Makkah, Saudi Arabia, pp. 113.

Al-Krargy, E. M, Doma, M. I. and Dawod, G. M. (2014), "Towards an Accurate Definition of the Local Geoid Model in Egypt using GPS/Levelling Data: A Case Study at Rosetta Zone", International Journal of Innovative Science and Modern Engineering, Vol. 2, Issue 11, pp. 10-15.

Ayer, J. (2008), "Transformation models and Procedures for Framework Integration of the Ghana National Geodetic Network", The Ghana Surveyor, Vol. 28, No. 1, pp. 52-58.

Ayer, J. and Fosu, C. (2008), "Map coordinates referencing and the use of GPS datasets in Ghana", Journal of Science and Technology, Vol. 28, No.1, pp. 116-127.

Ayer, J. and Tiennah, T. (2008), "Datum Transformation by the Iterative Solution of the Abridging Inverse Molodensky Formulae", The Ghana Surveyor, Vol. 1, No. 2, pp. 59-66.

Cai, G., Chen, B. M. and Lee, T. H. (2011), Unmanned rotorcraft systems, Advances in industrial control, Springer-Verlag London Limited, pp. 23-34.

Constantin-Octavian, A. (2006), “3D Affine coordinate transformations", Masters of Science Thesis in Geodesy No.3091 TRITAGIT EX 06-004, School Architecture and the Built Environment, Royal Institute of Technology (KTH), 10044 Stockholm, Sweden, $7 \mathrm{pp}$.

Deakin, R. E. (2004), “The standard and Abridged Molodensky Coordinate Transformation Formulae", Lecture Notes, Department of Mathematical and Geospatial Sciences, RMIT University, pp.1 - 21.

Deakin, R. E. (2006), Bursa-Wolf and Molodensky-Badekas Transformations, Lecture Notes, Department of Mathematical 
and Geospatial Sciences, RMIT University, pp. $1-21$.

Dzidefo, A. (2011), "Determination of Transformation Parameters between the World Geodetic System 1984 and the Ghana Geodetic Network", Master's Thesis, Department of Civil and Geomatic Engineering, Kwame Nkrumah University of Science and Technology, Kumasi, Ghana, pp. 49-50.

Ghilani, D. C. and Wolf, R. P. (2006), Adjustment Computations: Spatial Data Analysis, John Wiley \& Sons, Inc., 4th Ed., Hoboken, New Jersey, pp. 368-369.

Jekeli, C. (2012), "Geometric Reference Systems in Geodesy", Lecture Notes, Division of Geodetic Science, School of Earth Sciences Ohio State University, USA, $15 \mathrm{pp}$.

Karunaratne, F. L. (2007), "Finding out Transformation parameters and Evaluation of New Coordinate system in Sri Lanka", Master's Thesis, International Institute for Geoinformation Science and Earth Observation, Enschede, The Netherlands, 14 pp.

Kotzev, V. (2013), "Consultancy Service for the Selection of a New Projection System for Ghana." Draft Final Reports, World Bank Second Land Administration Project (LAP-2) Unpublished, $16 \mathrm{pp}$.

Kumi-Boateng, B. and Ziggah, Y. Y. (2016), "Accuracy Assessment of Cartesian (X,Y, Z) to Geodetic Coordinates $(\varphi, \lambda, \quad h)$ Transformation Procedures in Precise 3D Coordinate Transformation - A Case Study of Ghana Geodetic Reference Network" Journal of Geosciences and Geomatics, Vol. 4, No. 1, pp. $1-7$.

Molnár. G. and Timár, G. (2005), “Determination of the parameters of the Abridging Molodensky formulae providing the best horizontal fit", EGU General Assembly, Geophysical Research Abstracts, Vienna, Austria, Vol. 7, pp. 1-3.

Odera, P. A. (2016), “Assessment of EGM 2008 using GPS/levelling and free-air gravity anomalies over Nairobi County and its environs", South African Journal of Geomatics, Vol. 5, No. 1, pp. 17-30.

Pavlis, K. N., Holmes, S.A., Kenyon, S. C. and Factor, J. K. (2008), "An Earth Gravitational Model to Degree 2160", EGU General Assembly 2008, Vienna, Austria, pp.1.

Pavlis, K. N., Holmes, S.A., Kenyon, S. C. and Factor, J. K. (2012), "The Development and Evaluation of the Earth Gravitational Model 2008 (EGM 2008)", Journal of Geophysical Research, Vol. 117, Issue B16, p.4406.

Poku-Gyamfi, Y. and Schueler, T. (2008), "Renewal of Ghana's Geodetic Reference Network", 13th FIG Symposium on
Deformation Measurement and Analysis, 4th IAG Symposium on Geodesy for Geotechnical and Structural Engineering, LNEC, LISBON, pp. 1-9.

Uzodinma, V. N., Oguntuase J.O., Onah, E., Chike C. and Ehigiator, R. (2014), "Validation of EGM2008-Based Orthometric Heights in a Micro Environment in Nigeria", FIG Congress 2014 Engaging the Challenges - Enhancing the Relevance, Kuala Lumpur, Malaysia, pp.114.

Vanicek, P. and Steeves, R. R. (1996), "Transformation of coordinates between two horizontal geodetic datums" Journal of Geodesy, Vol. 70, pp. 740-745.

Ziggah, Y. Y., Youjian, H. and Odutola, C. A. (2013a), "Determination of GPS Coordinate Transformation Parameters of Geodetic Data between reference datums, A Case Study of Ghana Geodetic Reference Network", International Journal of Engineering Sciences and Research Technology, Vol. 2, Issue 4, pp. 2277-9655.

Ziggah, Y. Y., Youjian, H., Odutola, C.A. and Nguyen, T.T. (2013b), “Accuracy Assessment of Centroid Computation Methods in Precise GPS Coordinates Transformation Parameters Determination - A Case Study, Ghana", European Scientific Journal, Vol. 9, Issue 15, pp. 1857-7431.

Ziwu, F. D. (2011), "Determination of Free-Air Gravity Anomalies over Brong-Ahafo Region of Ghana", Master's Thesis, Kwame Nkrumah University of Science and Technology, Ghana, 36 pp.

\section{Authors}

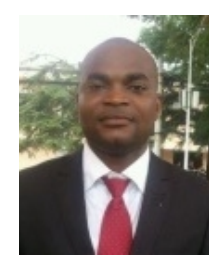

Yao Yevenyo Ziggah is an Assistant Lecturer at the Geomatic Engineering Department of the University of Mines and Technology (UMaT). He holds a BSc in Geomatic Engineering from UMaT and a MEng in Geodesy and Survey Engineering from China University of Geosciences (Wuhan). His research interests include geodetic deformation modelling, geoid modelling, geodetic coordinate transformation and application and development of Artificial Intelligence Techniques in Geodesy.

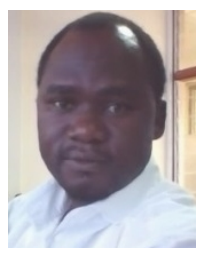

Dr Issaka Yakubu is a Lecturer at Geomatic Engineering Department of the University of Mines and Technology (UMaT), Tarkwa-Ghana. He holds a Certificate in Disaster Risk Management and Environ-mental Assessment for Spatial Planning from the International Institute for Geo-information Science and Earth Observation (ITC) -University of Twente, The Netherlands and Bachelor of Science degree in Geomatic Engineering from the Kwame Nkrumah University of Science and Technology, Kumasi-Ghana. He obtained his Master of Philosophy degree and Doctor of Philosophy from UMaT. His research interests include Global Navigation Satellite System (GNSS) and applications, Disaster Risk Management, Geographic 
Information System (GIS) and applications, Engineering/Cadastral Surveys and Fleet Management.

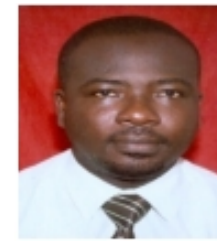

Dr Bernard Kumi-Boateng is a Senior

Lecturer at the Department of Geomatic Engineering of the University of Mines and Technology (UMaT), Tarkwa, Ghana. He holds a Bachelor of Science degree in Geomatic Engineering from the Kwame Nkrumah University of Science and Technology, Kumasi, Ghana. He obtained his Master of Science degree and Doctor of Philosophy from the International Institute for Geo-information Science and Earth Observation (ITC), Enschede-The Netherlands and UMaT respectively. His research interest includes application of Remote Sensing and GIS in Environmental Management, Spatial Statistics, Land and Compensation Surveys. 